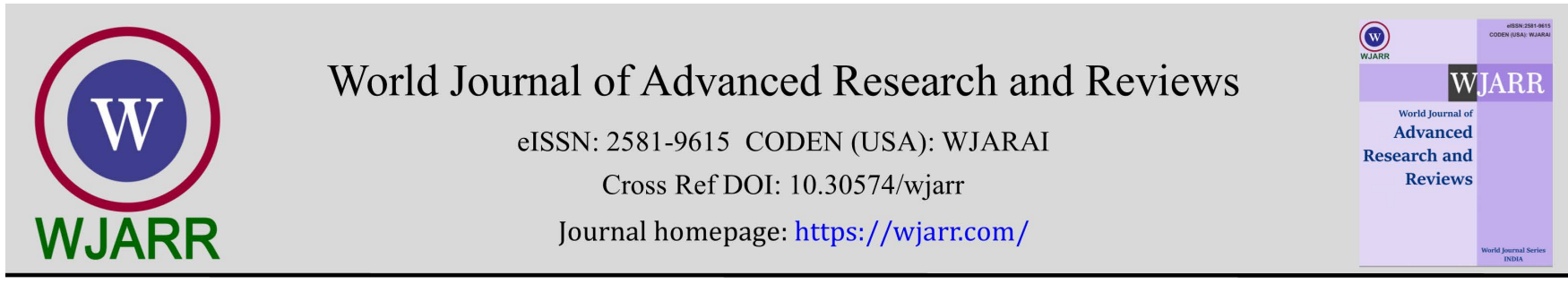

(RESEARCH ARTicle)

Check for updates

\title{
Stakeholders' individual and organizational capacity to acquire, assess, adapt and apply evidence for maternal, neonatal and child health in policymaking in Burkina Faso
}

Ermel Ameswué. Kpogbé. Johnson 1, ${ }^{*}$, Virgil Lokossou ${ }^{1}$, Moukaïla Amadou 1, Aristide Romaric Bado ${ }^{1}$, Gauthier Tougri ${ }^{2}$, Jesse Chigozie Uneke ${ }^{3}$ and Issiaka Sombié ${ }^{1}$

${ }^{1}$ West African Health Organisation (WAHO/ECOWAS) 01BP 153 Bobo-Dioulasso 01 Burkina Faso www.wahooas.org.

2 Unité de Gestion et de Transfert de Connaissances (UGTC), Ministère de la Santé, Burkina Faso.

${ }^{3}$ Knowledge Translation Platform, African Institute for Health Policy \& Health Systems, Ebonyi State University, PMB 053

Abakaliki, Nigeria.

World Journal of Advanced Research and Reviews, 2021, 10(01), 191-202

Publication history: Received on 07 March 2021; revised on 11 April 2021; accepted on 14 April 2021

Article DOI: https://doi.org/10.30574/wjarr.2021.10.1.0152

\begin{abstract}
Introduction: In Burkina Faso, the systematic use of research evidence in maternal, newborn and child health (MNCH) decision-making is not yet institutionalized despite previous initiatives to promote the evidence to policy link. This study aimed to assess individual and organizational capacities of MNCH stakeholders for evidence-to-policy link in Burkina Faso.
\end{abstract}

Methods: The design was a cross-sectional study conducted during a national MNCH stakeholders' engagement event organised in Ouagadougou in November 2015 by Burkina Faso Ministry of Health. A self-assessment survey using structured pre-tested questionnaire was administered to assess participants' individual and organisational capacities to acquire, appraise, adapt and apply evidence in decision-making.

Results: The mean rating (MNR) for individual knowledge about initiating/conducting research and ability to access and use existing research evidence ranged from 2.76-2.96 on the scale of 5. The MNR of the capacity to assess the authenticity, validity, reliability, quality and applicability of research evidence ranged from 2.72 to 3.08 . Respondents rated their organizational level of research incentives including availability of research grants, in-service research training, and provision of research facilities very low (MNR=1.60). The MNR of organizational capacity to initiate research, source for research evidence, assess the validity and applicability of research evidence, and incentives to encourage the application of research evidence ranged from 2.16 to 2.76 .

Conclusion: The outcome of this study demonstrates the urgent need for capacity enhancement at individual level for MNCH stakeholders in Burkina Faso and the creation of enabling environment for promotion of evidence use at organizational level, through research incentives.

Keywords: Assessment; Capacities; Individual; Organisational; Stakeholder; Decision-makers; Evidence; Maternal Health; Burkina Faso

\footnotetext{
${ }^{*}$ Corresponding author: Ermel Ameswue Kpogbé. Johnson; Tel: +226 7521 56 56; Email: jermel@wahooas.org

West African Health Organisation (WAHO/ECOWAS) 01BP 153 Bobo-Dioulasso 01 Burkina Faso www.wahooas.org. 


\section{Introduction}

Burkina Faso is one of the countries in sub-Saharan Africa that was not able to achieve the health-related Millennium Development Goals (MDGs) [1]. Despite the health interventions implemented within the last decade in Burkina Faso, morbidity and mortality indicators remain alarming in the country [2-4]. Malaria, respiratory infections and diarrhoeal diseases were the top three causes of hospital consultation in Burkina Faso in 2016 [5] and are the leading combined causes of morbidity and mortality [3,4]. The recognition of the importance of use of research findings and other types of evidence in the development of health policies and programs is growing globally [6-9]. However, while the recognition of the value of evidence and research findings in health decision-making and practice are is increasing in momentum world-wide [10-12], the culture of use of evidence in policymaking is not well established in Burkina Faso.

In a systematic review, Olivier and colleagues [13], identified the availability/accessibility of evidence, the clarity/relevance of research results and the capacities of decision-makers as the most frequently cited factors in the literature, limiting the use of evidence in decision-making and practice. Although other factors such as researchers' collaboration with decision-makers, organizational structure, availability of resources and timeliness in provision of evidence, all play contributory roles to influence the use of evidence [13-17], there is a general consensus that good and strong capacities and skills are needed for decision-makers to search for evidence, evaluate relevance, adapt it and use it in decision-making or practice [13,16-19].

In Burkina Faso, there have been a number of initiatives to promote the use of evidence by decision-makers [20-25]. The Evidence Informed Policy Network Africa (EVIPNet-Africa) initiative launched by the World Health Organization (WHO) in 2006 had Burkina Faso as part of the initiative [26]. Thus, EVIPNet-Burkina Faso had the mandate in part, to build capacity for evidence-informed decision-making culture. This initiative made it possible to produce a policy brief on strategies to reduce maternal mortality in Burkina Faso [27] validated it at a deliberative workshop [28], developed an action plan for the implementation of EVIPNet-Burkina Faso[29] and implemented a rapid response service within the Ministry of Health[21].

From the perspective of building on existing knowledge and sustaining interventions, it is important to assess individual knowledge about the use of evidence and organisational capacities to foster the culture of decision-making and evidence-based practice prior to any intervention. In doing so, this approach allows interventions to be adapted to the realities of the context. There is dearth of literature on assessment of stakeholders' knowledge prior to interventions for evidence use in policymaking Burkina Faso, and reports on organisational capacities to promote the use of evidence in general and particularly in maternal, new-born and child health are essentially lacking.

In 2015, the West African Health Organization (WAHO), the specialized health institution of the Economic Community of West African States (ECOWAS), conducted a situation analysis on the use of evidence in maternal, new-born and child health. This study was part of the regional project to promote the use of evidence called "Moving maternal new-born and child health Evidence into Policy in West Africa (MEP)", which covered six countries in the sub-region, including Benin, Burkina Faso, Ghana, Mali, Nigeria and Senegal. This article presents the results of the situation analysis of the capacities and knowledge of maternal and child health stakeholders in Burkina Faso in terms of knowledge transfer and the use of evidence in decision-making.

\section{Methods}

The study assessed individual and organisational capacities of maternal, new-born and child health (MNCH) stakeholders including policymakers from the Ministry of Health in Burkina Faso. The study was designed as a crosssectional study. A two-day stakeholders' engagement event was organised in Ouagadougou in November 2015, under the auspices of the Family Health Department of the Burkina Faso Ministry of Health and with the support of the West African Health Organisation (WAHO).

During the meeting, a self-assessment survey using structured pre-tested questionnaire was conducted to assess individual and organisational capacities for evidence use in policymaking by the stakeholders. Participants consent was obtained prior to the administration of the questionnaire.

This study was part of a previous investigation conducted in six West African countries (Benin, Burkina Faso, Ghana, Mali, Nigeria and Senegal) and the method was previously described in previous studies focused on Nigeria [30]. The questionnaire developed was based on the self-assessment tool of the Canadian Health Services Research Foundation (CHSRF) [31] which was translated in French for the participants. The questionnaire contained the following 
components: socio-demographic information, Individual knowledge and application of Information and communication technologies, Individual and organisational capacities for acquisition, appraisal and application of evidence in MNCH policymaking. The items of the questionnaire were rated using the Likert scale of 1 to 5 points, where 1 point = "grossly inadequate"; 2 points = "inadequate"; 3 points = "fairly adequate"; and 4 points = "adequate"; and 5 points= "very adequate".

The data collected via the questionnaires was analysed using the methods developed by Johnson and Lavis [32] and also by using Stata 11. A descriptive analysis was carried performed using position parameters (mean rating, median rating) and range parameters (minimal, maximal, range) as described in a previous study [16]. The mean values obtained ranging from 1.00 to 3.49 points were considered as low while the mean values ranging from 3.50 to 5.00 points are considered as high.

\section{Results}

All the 25 participants who attended the stakeholders' engagement event consented to participate to the study and completed the questionnaire.

\subsection{Personal information}

The socio-demographic profiles of participants are summarized in Table 1. Most of the participants were males (68\%) and over 35 years of age (80\%). They came from the Ministry of Health (28\%), the regional level (28\%) or the health district where they held the positions of Director (20\%), Programme Officer (28\%) and Health Practitioner (40\%). Most of the participants have been in their jobs for no more than 2 years (84\%).

Table 1 Profile and institution of provenance characteristics of participants.

\begin{tabular}{|l|l|}
\hline Personal data & Outcomes (\%) \\
\hline Sex & \\
Female & $8(32.0)$ \\
Male & $17(68.0)$ \\
Total & 25 \\
\hline Age category (years) & \\
$25-35$ & $5(20.0)$ \\
$35-45$ & $13(52.0)$ \\
Above 45 & $7(28.0)$ \\
Total & 25 \\
\hline Type of institution/organisation & \\
Ministry of Health/Family Health Department & $7(28.0)$ \\
Regional/provincial Health Branch & $7(28.0)$ \\
Health District/Regional hospital & $5(20.0)$ \\
University/ Research centre & $2(8.0)$ \\
Civil society organisation & $4(16.0)$ \\
Total & 25 \\
\hline Current designation/position in the organisation & \\
Director & $5(20.0)$ \\
Programme manager/advisor/assistant & $7(28.0)$ \\
Care providers (Physician/nurse/midwife) & $10(40.0)$ \\
Teacher-researcher & $2(8.0)$ \\
Total & 25 \\
\hline Duration in the designation/position (years) & \\
Under 3 & $21(84.0)$ \\
\hline
\end{tabular}




\begin{tabular}{|l|l|}
\hline$[4-5]$ & $1(4.0)$ \\
{$[6-10]$} & $1(4.0)$ \\
Above 10 & $2(8.0)$ \\
Total & 25 \\
\hline Level of intervention of the institution & \\
Primary level & $3(12.0)$ \\
Secondary level & $9(36.0)$ \\
Tertiary level & 13 \\
Total & 25 \\
\hline
\end{tabular}

\subsection{Knowledge and application of Informatics and Communication Technologies:}

The outcomes of participants' knowledge and application of informatics and communication technologies are presented in the Table 2. The participants had basic knowledge in computer software application (64\%). A total of $84 \%$ of the respondents noted that they used the computer for database management and analysis.

Table 2 Outcomes of participants' knowledge and application of informatics and communication technologies.

\begin{tabular}{|l|l|}
\hline $\begin{array}{l}\text { Knowledge and application of informatics and } \\
\text { communication technologies }\end{array}$ & No. (\%) \\
\hline $\begin{array}{l}\text { Level of knowledge in informatics } \\
\text { Basic computer skills }\end{array}$ & $9(36.0)$ \\
Basic computer software application & $16(64.0)$ \\
Total & 25 \\
\hline Type of computer usage & \\
Secretarial task & $4(16.0)$ \\
Database management & $11(44.0)$ \\
Data analysis & $10(40.0)$ \\
Total & 25 \\
\hline Frequency of internet use & \\
Very frequently & $8(32.0)$ \\
Frequently & $13(52.0)$ \\
Occasionally & $4(16.0)$ \\
Total & 25 \\
\hline
\end{tabular}

\subsection{Participants' knowledge about evidence}

The Table 3 summarizes the outcomes of participants' knowledge about evidence. The mean rating of level of knowledge of evidence databases and capacity to identify and obtain relevant evidence from databases online bibliographies were 2.68 and 2.84 respectively on the scale of 5 .

Table 3 Outcomes of participant's knowledge on evidence.

\begin{tabular}{|l|l|l|l|}
\hline Knowledge about evidence & Mean \pm Std. Dev. & Median & Range scale* \\
\hline Level of knowledge of evidence databases (total= 25) & $2.68 \pm 0.94$ & 2 & $2-5$ \\
\hline $\begin{array}{l}\text { Capacity to identify and obtain relevant evidence from } \\
\text { databases online bibliographies (total = 25) }\end{array}$ & $2.84 \pm 1.07$ & 3 & $1-5$ \\
\hline
\end{tabular}

*Range scale: 1=Grossly inadequate, 2=Inadequate, 3=Fairly adequate, 4=Adequate, 5=Very adequate 


\subsection{Individual capacities to acquire appraise and apply evidence in decision-making}

The outcome of the assessment of the individual capacities to acquire appraise and apply evidence in decision-making is presented in Table 4. The mean rating for individual knowledge about initiating/conducting research was 2.96, while the mean rating of the ability to access and use existing research evidence was 2.76 on the scale of 5 . The mean rating of the capacity to assess the authenticity, validity, reliability \& high quality of research evidence and the relevance/applicability of research evidence and summarize research results in a user-friendly way ranged from 2.72 to 3.08 on the scale of 5 . The mean rating of the ability to present results of research to decision makers using charts, tables, graphs, pictogram, and bullet/power point presentations was 3.08 .

Table 4 Outcomes of individual capacities to acquire appraise and apply evidence in decision-making (N-25).

\begin{tabular}{|c|c|c|c|c|}
\hline Parameter assessed & Description & $\begin{array}{l}\text { Mean } \\
\pm \text { Std. Dev. }\end{array}$ & Median & $\begin{array}{l}\text { Range } \\
\text { scale* }\end{array}$ \\
\hline $\begin{array}{l}\text { Knowledge } \\
\text { initiating/conducting research } \\
\text { in general and in maternal, } \\
\text { new-born \& child health } \\
\text { specifically }\end{array}$ & $\begin{array}{l}\text { Identification of research problems; } \\
\text { construction of research questions; } \\
\text { designing of research methodology; } \\
\text { writing research } \\
\text { proposals/protocols; analysis \& } \\
\text { interpretation of research results; } \\
\text { writing of research reports. }\end{array}$ & $2.96 \pm 0.93$ & 3 & $2-5$ \\
\hline $\begin{array}{l}\text { Ability to access and use } \\
\text { existing research evidence in } \\
\text { general and in maternal, new- } \\
\text { born \& child health specifically }\end{array}$ & $\begin{array}{l}\text { Journals, internet \& library assess; non } \\
\text { journal reports e.g. newspapers, } \\
\text { textbooks, reports from national \& } \\
\text { international agencies, databases, } \\
\text { websites; works from researchers \& } \\
\text { peers. }\end{array}$ & $2.76 \pm 0.97$ & 3 & $1-5$ \\
\hline \multirow{2}{*}{$\begin{array}{l}\text { Capacity to assess the } \\
\text { authenticity, validity, reliability } \\
\text { \& high quality of research } \\
\text { evidence in general and in } \\
\text { maternal, new-born \& child } \\
\text { health specifically }\end{array}$} & $\begin{array}{l}\text { The skill to evaluate } \& \text { appropriate the } \\
\text { quality of research methodology. }\end{array}$ & $2.88 \pm 1.05$ & 3 & $1-5$ \\
\hline & $\begin{array}{l}\text { The skill to evaluate the reliability of } \\
\text { specific research evidence and to } \\
\text { compare research methods and results. }\end{array}$ & $2.72 \pm 1.02$ & 3 & $1-5$ \\
\hline \multirow{2}{*}{$\begin{array}{l}\text { Capacity to assess the relevance } \\
\text { and applicability of research } \\
\text { evidence in general and in } \\
\text { maternal, new-born \& child } \\
\text { health specifically }\end{array}$} & $\begin{array}{l}\text { The skill to identify relevant similarities } \\
\text { and differences between research } \\
\text { evidence. }\end{array}$ & $2.72 \pm 0.98$ & 3 & $1-4$ \\
\hline & $\begin{array}{l}\text { The skill to evaluate the differences in } \\
\text { the research evidences in the context of } \\
\text { your team. }\end{array}$ & $2.88 \pm 0.97$ & 3 & $1-4$ \\
\hline \multirow{3}{*}{$\begin{array}{l}\text { How would you describe your } \\
\text { ability to summarize research } \\
\text { results in a user-friendly way in } \\
\text { general and in maternal, new- } \\
\text { born \& child health specifically }\end{array}$} & $\begin{array}{l}\text { Present research results concisely in } \\
\text { accessible language }\end{array}$ & $3.04 \pm 0.79$ & 3 & $1-4$ \\
\hline & $\begin{array}{l}\text { Synthesize in one document relevant } \\
\text { research as well as information and } \\
\text { analysis from other sources. }\end{array}$ & $2.76 \pm 0.31$ & 3 & $2-4$ \\
\hline & $\begin{array}{l}\text { Link the research results to key issues } \\
\text { and provide recommendations. }\end{array}$ & $3.08 \pm 0.76$ & 3 & $1-4$ \\
\hline $\begin{array}{l}\text { ability to present results of } \\
\text { research to decision makers in } \\
\text { general and in maternal, new- } \\
\text { born \& child health specifically }\end{array}$ & $\begin{array}{l}\text { Use of charts, tables, graphs, pictogram, } \\
\text { bullet/power point presentations, etc. }\end{array}$ & $3.08 \pm 0.86$ & 3 & $2-5$ \\
\hline
\end{tabular}

*Range scale: $1=$ Grossly inadequate, 2 =Inadequate, $3=$ =Fairly adequate, $4=$ Adequate, $5=$ Very adequateTable 5 Outcomes of the assessment organisational capacities to promote the use evidence through incentives in MNCH decision making (N-25) 


\subsection{Organisational capacities to promote the use evidence through incentives in decision making}

The mean ratings of the organisational capacities to promote the use evidence through incentives in decision making were generally low (Table 5). Respondents rated very low their organizational level of research incentives including availability of research grants; award of honours/promotions; in-service training; stipends, bonuses \& per-diem for research works; provision of research facilities etc. The mean rating for this was as low as 1.60 on the scale of 5 . The mean rating of the organizational capacity to initiate research, source for research evidence, assess the validity, quality and applicability of research evidence, and incentives to encourage the application of research evidence ranged from 2.16 to 2.76 on the scale of 5 .

Table 5 Outcomes of the assessment organisational capacities to promote the use evidence through incentives in MNCH decision making (N-25).

\begin{tabular}{|c|c|c|c|c|}
\hline Parameter assessed & Description & $\begin{array}{l}\text { Mean } \\
\pm \text { Std. Dev. }\end{array}$ & Median & $\begin{array}{l}\text { Range } \\
\text { scale* }^{*}\end{array}$ \\
\hline $\begin{array}{l}\text { The capacity of your team to } \\
\text { initiate research in general and in } \\
\text { maternal, new-born \& child } \\
\text { health specifically }\end{array}$ & $\begin{array}{l}\text { Existence of research programmes, } \\
\text { departments, officers \& facilities; any } \\
\text { reputation on specialized areas of } \\
\text { research; research outputs; regularity of } \\
\text { research activities. }\end{array}$ & $2.76 \pm 1.01$ & 2 & $1-5$ \\
\hline $\begin{array}{l}\text { The capacity of your Team to } \\
\text { source for research evidence in } \\
\text { general and in maternal, new- } \\
\text { born \& child health specifically }\end{array}$ & $\begin{array}{l}\text { Existence of databases; relationship with } \\
\text { research institutions; collaboration with } \\
\text { researchers \& experts; commissioning of } \\
\text { research projects }\end{array}$ & $2.60 \pm 1.00$ & 2 & $1-5$ \\
\hline $\begin{array}{l}\text { The level of research incentives } \\
\text { available in your Team in general } \\
\text { and in maternal, new-born \& child } \\
\text { health specifically }\end{array}$ & $\begin{array}{l}\text { Availability of library, internet facilities; } \\
\text { availability of research grants; award of } \\
\text { honours/promotions; in-service training; } \\
\text { stipends, bonuses \& per-diem for research } \\
\text { works; provision of research facilities; } \\
\text { sponsorship to conferences/workshops; } \\
\text { institutional subscription of research } \\
\text { materials (periodicals eg. journals), } \\
\text { databases, websites. }\end{array}$ & $1.60 \pm 0.91$ & 2 & $1-4$ \\
\hline $\begin{array}{l}\text { Incentives for assessment of the } \\
\text { validity, quality and applicability } \\
\text { of research evidence in general } \\
\text { and in maternal, new-born \& child } \\
\text { health specifically }\end{array}$ & $\begin{array}{l}\text { Use of consultants; application of computer } \\
\text { software, statistical package; well- } \\
\text { equipped laboratory; existence of quality } \\
\text { control units; promotion of ethical } \\
\text { standards/practices }\end{array}$ & $2.04 \pm 0.98$ & 2 & $1-5$ \\
\hline $\begin{array}{l}\text { Incentives to encourage the } \\
\text { application of research evidence } \\
\text { in general and in maternal, new- } \\
\text { born \& child health specifically }\end{array}$ & $\begin{array}{lr}\text { Availability of } \quad \text { research } & \text { evidence } \\
\text { implementation committee; availability of } \\
\text { administrative } \quad \text { process } & \text { for } \\
\text { accepting/implementing } & \text { research } \\
\text { evidence. }\end{array}$ & $2.16 \pm 1.07$ & 2 & $1-5$ \\
\hline $\begin{array}{l}\text { Incentives to encourage the } \\
\text { provision of research evidence to } \\
\text { decision makers in general and in } \\
\text { maternal, new-born \& child } \\
\text { health specifically }\end{array}$ & $\begin{array}{l}\text { Summarized and easy-to-use research } \\
\text { evidence is routinely brought to the } \\
\text { attention of relevant decision makers (such } \\
\text { as through regular meetings or reports; or } \\
\text { participation by researchers/analysts in } \\
\text { management meetings to present/discuss } \\
\text { evidence). }\end{array}$ & $2.44 \pm 0.96$ & 2 & $1-5$ \\
\hline
\end{tabular}

*Range scale: 1 =Grossly inadequate, 2 =Inadequate, $3=$ Fairly adequate, 4=Adequate, $5=$ Very adequateTable 6 Outcomes of the assessment organisational value of use of research evidence in MNCH decision making (N-25). 


\subsection{Organisational value of use of research evidence in decision making}

Table 6 summarizes the outcome of the assessment of organisational value of use of research evidence in decision making. The mean ratings recorded were generally low, for organization's use of research a priority (2.04), organisation's activities which encourage using research (2.08), management and front-line staff support to discussing research evidence related to the organisation's main goals (2.68), and organisation's communication channels encouraging evidence exchange (2.40).

Table 6 Outcomes of the assessment organisational value of use of research evidence in MNCH decision making (N-25).

\begin{tabular}{|c|c|c|c|c|}
\hline Parameter assessed & Description & $\begin{array}{l}\text { Mean } \\
\pm \text { Std. Dev. }\end{array}$ & Median & $\begin{array}{l}\text { Range } \\
\text { scale* }\end{array}$ \\
\hline \multirow[t]{6}{*}{$\begin{array}{l}\text { Example of research } \\
\text { valued in general and in } \\
\text { maternal, new-born \& } \\
\text { child health specifically }\end{array}$} & $\begin{array}{l}\text { Using research is a priority: our organisation } \\
\text { has committed sufficient people, time, } \\
\text { training and budgets to access, appraise, } \\
\text { adapt and apply research in making } \\
\text { decisions. }\end{array}$ & $2.04 \pm 1.02$ & 2 & $1-5$ \\
\hline & $\begin{array}{l}\text { Our organisation's job descriptions and } \\
\text { performance incentives include enough } \\
\text { focus on activities which encourage using } \\
\text { research. }\end{array}$ & $2.08 \pm 1.11$ & 2 & $1-5$ \\
\hline & $\begin{array}{l}\text { Both management and front-line staff } \\
\text { support and participate in frequent forum } \\
\text { where staff and invitees present and discuss } \\
\text { research evidence related to the } \\
\text { organisation's main goals. }\end{array}$ & $2.68 \pm 1.03$ & 3 & $1-5$ \\
\hline & $\begin{array}{l}\text { Management has clearly communicated } \\
\text { corporate strategy and priority areas for } \\
\text { improvement, so that people creating or } \\
\text { monitoring research evidence know what is } \\
\text { needed. }\end{array}$ & $2.48 \pm 1.08$ & 2 & $1-5$ \\
\hline & $\begin{array}{l}\text { Our organisation has effective } \\
\text { communication channels so that priorities, } \\
\text { evidence and ideas are exchanged across } \\
\text { divisions, as well as between management } \\
\text { and front lines. }\end{array}$ & $2.40 \pm 1.08$ & 2 & $1-5$ \\
\hline & $\begin{array}{l}\text { Our corporate culture is to value and reward } \\
\text { flexibility, change, and continuous quality } \\
\text { improvement, and we provide adequate } \\
\text { resources at all levels to support change. }\end{array}$ & $2.36 \pm 0.95$ & 2 & $1-4$ \\
\hline
\end{tabular}

\subsection{Place of research in decision making at organisational level}

The mean ratings for the assessment of place of research in decision making at organisational level was generally low (Table 7). The mean rating for the consideration of research results and other evidence during decision making was 2.44. While the mean rating for staff knowing when they can contribute evidence when major decisions are made was will be made was 2.36 . The mean rating for staff providing evidence and analysis in the discussion before a decision was as low as 2.88. 
Table 7 Outcomes of the assessment of place of research in decision making at organisational level (N-25).

\begin{tabular}{|c|c|c|c|c|}
\hline Parameter assessed & Description & $\begin{array}{l}\text { Mean } \\
\pm \text { Std. Dev. }\end{array}$ & Median & $\begin{array}{l}\text { Range } \\
\text { scale* }\end{array}$ \\
\hline \multirow[t]{6}{*}{$\begin{array}{l}\text { Place for research in decision } \\
\text { making processes in general } \\
\text { and in maternal, new-born \& } \\
\text { child health specifically }\end{array}$} & $\begin{array}{l}\text { When we make major decisions, we usually } \\
\text { allow enough time to identify researchable } \\
\text { questions and create/ obtain, analyse and } \\
\text { consider research results and other } \\
\text { evidence. }\end{array}$ & $2.44 \pm 0.87$ & 2 & $1-5$ \\
\hline & $\begin{array}{l}\text { Our management team has enough } \\
\text { expertise to evaluate the feasibility of each } \\
\text { option, including potential impact across } \\
\text { the organisation as well as on its clients, } \\
\text { partners and other stakeholders. }\end{array}$ & $2.52 \pm 1.05$ & 2 & $1-5$ \\
\hline & $\begin{array}{l}\text { When staff develop or identify high quality } \\
\text { and relevant research, decision makers will } \\
\text { usually give formal consideration to any } \\
\text { resulting recommendations }\end{array}$ & $2.52 \pm 0.92$ & 2 & $1-4$ \\
\hline & $\begin{array}{l}\text { Staff and appropriate stakeholders know } \\
\text { when and how major decisions will be } \\
\text { made, how and when they can contribute } \\
\text { evidence and how that information will be } \\
\text { used }\end{array}$ & $2.36 \pm 0.81$ & 2 & $1-4$ \\
\hline & $\begin{array}{l}\text { The staff who have provided evidence and } \\
\text { analysis usually participate in the } \\
\text { discussion before a decision is made and, } \\
\text { when possible, so do relevant non-staff } \\
\text { researchers }\end{array}$ & $2.32 \pm 0.80$ & 2 & $1-4$ \\
\hline & $\begin{array}{l}\text { When a decision is made, feedback to staff } \\
\text { and appropriate stakeholders includes a } \\
\text { rationale for the decision, and review of } \\
\text { how the available evidence influenced the } \\
\text { choices made }\end{array}$ & $2.28 \pm 0.54$ & 2 & $1-3$ \\
\hline
\end{tabular}

*Range scale: $1=$ =Grossly inadequate, $2=$ =Inadequate, 3=Fairly adequate, 4=Adequate, 5=Very adequate

\section{Discussion}

This study to the best of our knowledge represents the first attempt to systematically assess the MNCH stakeholders' individual and organizational capacity to acquire, assess, adapt and apply evidence in policymaking in Burkina Faso. Interestingly, the study outcome showed a generally low mean ratings in both individual and organizational capacity for use of research evidence in policymaking. Of the 30 parameters assessed relevant to individual and organizational capacity to use evidence for policymaking only $3(10 \%)$ had mean ratings of up to 3 points on the scale of 5 . This was unlike a similar study we conducted in Nigeria among MNCH stakeholders of which out of the 28 parameters assessed on individual and organizational capacity for evidence informed policymaking 19(67.9\%) had mean ratings of 3 and above [16].

The outcome of this study therefore, clearly suggests that in Burkina Faso and among the MNCH policymakers there exist grossly deficient capacity for the evidence-informed policymaking. A number of previous reports have shown that many individuals occupying policymaking positions at government ministries lack the critical competency to acquire, assess and adapt research evidence in policymaking, which has resulted to a general lack of understanding about how evidence can be effectively used [33,34]. This calls for urgent introduction of mechanisms that will improve both organizational and individual capacity for evidence-to-policy link in Burkina Faso as a matter of utmost priority.

In this study, the mean ratings for individual capacities to acquire, appraise and apply evidence in decision-making were generally below 3 points on the scale of 5 . This outcome suggests the existence of capacity constraint in the knowledge 
about initiating/conducting research, access and use of available research evidence, assessment of the authenticity, validity, reliability \& high quality of research evidence and applicability of research evidence. The existence of these capacity constraints may be playing a contributory role to the lack of effective use of evidence in policymaking among MNCH policymakers in Burkina Faso.

Some previous studies that investigated the barriers and facilitators of the use of evidence in program management and in decision making noted that a deficit in the skills and experience of decision-makers in research literacy and research utilization, and a lack of formal management training constituted major barriers to evidence-use in policymaking and policy implementation [35-37]. Furthermore, in a similar study which assessed the capacity of decision makers to acquire, assess, adapt, and apply research evidence, the greatest capacity deficiency was observed in the domains related to: acquiring research; assessing the reliability, quality, relevance, and applicability of research evidence[38]. These findings further reinforce the assertion that policymakers research capacity development is imperative if evidence informed policymaking will become a reality and a culture in government ministries in Burkina Faso.

It was interesting to observe in this study that the mean ratings of the organisational capacities to promote evidence use through incentives in decision making, and the ratings for value placed on research in decision making at organisational level were generally below 3 points on the scale of 5. It was of great concern that respondents rated very low their organizational level of research incentives to encourage use of evidence in policymaking. The implication of this finding is that there may exist a very poor research enabling environment in the participants' organizations as observed in the previous studies conducted among policymakers in Nigeria [16,18]. Elsewhere, it was observed that policymaking organizations had limited incentives for research use, and also lack reasonable resources for assessing the quality and reliability of research[38].

Organizational capacity constraints for evidence informed policymaking have continued to hamper the evidence-topolicy-to-practice process. The key denominators common in the findings of a number of studies that have investigated organizational constraint in evidence use for policymaking were the lack of a research learning culture and institution of good management - that promote better decision-making [37,39-41]. Uneke and colleagues [42], noted that the existence of capacity constraints at organizational level poses a critical challenge to the evidence-informed policymaking because inadequate organizational commitment towards the promotion of research incentives can incapacitate even the highly knowledgeable and skilful policymaker in such organization.

\section{Conclusion}

In conclusion, the outcome of this study demonstrates the urgent need for capacity enhancement at individual level for MNCH stakeholders in Burkina Faso and the creation of enabling environment for promotion of evidence use at organizational level, through research incentives. Capacity development for policymakers on evidence informed policymaking has been identified as one of the major facilitators of evidence to policy process in government ministries [43]. According to Bennet and Green [44], evidence-based skills training is very important and educating administrative officials who can then introduce new decision-making approaches to their agency is an important way to effect systemic change. As the evidence to policy process is very dynamic, it is recommended that the capacity enhancement process be institutionalized in government ministries and among decision makers to keep them abreast with current global developments in the bridging of the evidence-policy gap

\section{Compliance with ethical standards}

\section{Acknowledgments}

"This work was carried out with the aid of a grant from the Innovating for Maternal and Child Health in Africa initiativea partnership of Global Affairs Canada (GAC), the Canadian Institutes of Health Research (CIHR) and Canada's International Development Research Centre (IDRC)." Under the grant [107892-001].

We thank the Department of Family Health of the Ministry of Health of Burkina Faso and the stakeholders who consented to participate at the stakeholder validation workshop. Specially thank to Dr André Zida, the consultant who provide support in conducting this study.

\section{Disclosure of conflict of interest}

The authors declare no competing interest. 


\section{Statement of informed consent}

Informed consent was obtained from all individual participants included in the study.

\section{Authors' contributions}

All the authors conceptualised and designed the study. EJ and AB analysed the data. EJ and IS drafted the manuscript. CJU reviewed and edited the manuscript. VL, AM and GT supported in the implementation of the study and made comments on the manuscript. All the authors approved the final version the manuscript.

\section{References}

[1] Nations Unies. Évaluation Des Progrès Réalisés En Afrique Pour Atteindre Les Objectifs Du Millénaire Pour Le Développement. 2015.

[2] Institute for Health Metrics and Evaluation (IHME). GBD Compare. 2015. Accessed on 12 November 2020. Available from: http://vizhub.healthdata.org/gbd-compare

[3] Institute for Health Metrics and Evaluation (IHME). Burkina Faso | Institute for Health Metrics and Evaluation. September 2016. Accessed on 12 November 2020. Available from: http://www.healthdata.org/burkina-faso

[4] World Health Organisation (WHO). Burkina Faso: WHO statistical profile. 2015; 3.

[5] Institut national de la statistique et de la démographie (INSD). Annuaire Statistique. 2016. 2017.

[6] Sanderson I. Evaluation, Policy Learning and Evidence-Based Policy Making. Public Adm. 2002; 80(1): 1-22.

[7] Klein R. From evidence-based medicine to evidence-based policy ? J Heal Serv Res Policy. 2000; 5(2): 65-66.

[8] Banks G. Evidence-based policy-making: What is it? How do we get it? ANZSOG/ANU Public Lect Ser. 2009; (August 2008): 1-27.

[9] Hanney SR, Gonzalez-Block MA, Buxton MJ, Kogan M. The utilisation of health research in policy-making: concepts, examples and methods of assessment. Heal Res Policy Syst. 2003; 1(1): 2.

[10] WALT G, GILSON L. Reforming the health sector in developing countries: the central role of policy analysis. Health Policy Plan. 1994; 9(4): 353-370.

[11] DeRuyter AJ, Ying X, Budd EL, Furtado K, Reis R, Wang Z, et al. Comparing Knowledge, Accessibility, and Use of Evidence-Based Chronic Disease Prevention Processes Across Four Countries. Front Public Heal. 2018; 6(August): 1-12.

[12] IDRC. Using evidence to reduce maternal deaths in Nigeria | IDRC - International Development Research Centre. 2016.

[13] Oliver K, Innvar S, Lorenc T, Woodman J, Thomas J. A systematic review of barriers to and facilitators of the use of evidence by policymakers. BMC Health Services Research. 2014; 14(1): 2.

[14] Salbach NM, Jaglal SB, Korner-Bitensky N, Rappolt S, Davis D. Practitioner and Organizational Barriers to Evidence-based Practice of Physical Therapists for People With Stroke. Phys Ther. 2007 ;87(10): 1284-1303.

[15] Black N, Donald A. Evidence based policy: proceed with care Commentary: research must be taken seriously. BMJ. 2001; 323(7307): 275-279.

[16] Uneke CJ, Sombie I, Keita N, Lokossou V, Johnson E, Ongolo-Zogo P, et al. Assessment of policy makers' individual and organizational capacity to acquire, assess, adapt and apply research evidence for maternal and child health policy making in Nigeria: a cross-sectional quantitative survey. Afr Health Sci. 2017; 17(3): 700-711.

[17] HENNINK M, STEPHENSON R. Using Research to Inform Health Policy: Barriers and Strategies in Developing Countries. J Health Commun. 2005; 10(2): 163-180.

[18] Uneke CJ, Ezeoha AE, Ndukwe CD, Oyibo PG, Onwe F, Igbinedion EB, et al. Individual and organisational capacity for evidence use in policy making in Nigeria: an exploratory study of the perceptions of Nigeria health policy makers. Evid Policy A J Res Debate Pract. 2011; 7(3): 251-276.

[19] Innvaer S, Vist G, Trommald M, Oxman A. Health policy-makers' perceptions of their use of evidence: a systematic review. J Heal Serv Res Policy. 2002; 7. 
[20] Zida A, Lavis JN, Sewankambo NK, Kouyate B, Moat K. The factors affecting the institutionalisation of two policy units in Burkina Faso's health system: a case study. Heal Res Policy Syst. 2017; 15(1): 62.

[21] Zida A, Lavis JN, Sewankambo NK, Kouyate B, Moat K, Shearer J. Analysis of the policymaking process in Burkina Faso's health sector: case studies of the creation of two health system support units. Heal Res Policy Syst. 2017; 15(1): 10.

[22] Dagenais C, Queuille L, Ridde V. Evaluation of a knowledge transfer strategy from a user fee exemption program for vulnerable populations in Burkina Faso. Glob Health Promot. 2013; 20(SUPPL.1): 70-79.

[23] Dagenais C, Somé TD, Boileau-Falardeau M, McSween-Cadieux E, Ridde V. Collaborative development and implementation of a knowledge brokering program to promote research use in Burkina Faso, West Africa. Glob Health Action. 2015; 8(1).

[24] Dagenais C, McSween-Cadieux E, Somé P-A, Ridde V. A Knowledge Brokering Program in Burkina Faso (West Africa): Reflections from Our Experience. Heal Syst Reform. 2016; 2(4): 367-372.

[25] Sween-cadieux EM, Dagenais C, Bonnet E, Somé P, Ridde V, Dagenais C, et al. Enjeux de l' évaluation mixte en transfert de connaissances : un exemple en sécurité routière au Burkina Faso. In: Oser les défis des méthodes mixtes en sciences sociales et sciences de la santé. 2018; 157-172.

[26] WHO. EVIPNet Regional and Country pages. WHO. 2012. Accessed on 10 December 2020. Accessed on 12 December 2020. Available from: https://www.who.int/evidence/resources/country_reports/en/

[27] Sanon Ouédraogo D, Ki Ouedraogo S, Kouyaté B. Mise en œuvre de stratégies porteuses pour la réduction de la mortalité maternelle au Burkina Faso (Note de politique SURE). 2010.

[28] KI Ouedraogo S, Gbangou A. Rapport du forum deliberatif relatif a la note de politique sur la « mise en reduction de la mortalite maternellle au Burkina Faso. 2011. Accessed on 10 December 2020. Available from: https://www.who.int/evidence/resources/country_reports/ForumRMM2011.pdf?ua=1

[29] Ministère de la Santé. Plan d' action 2010-2013 de mise en œuvre de l' iniative evipnet au Burkina Faso: amelioration de l'utilisation des resultats de recherche pour la santé. 2010.

[30] Uneke CJ, Sombie I, Keita N, Lokossou V, Johnson E, Ongolo-Zogo P. An assessment of policymakers' engagement initiatives to promote evidence informed health policy making in Nigeria. Pan Afr Med J. 2017; 27: 1-12.

[31] Canadian Health Services Research Foundation (CHSRF). Validating the Foundation's Self-assessment tool: A summary. 2008. Ottowa, Canada.

[32] Johnson NA, Lavis JN. 'Overview' in Procedures Manual for the 'Evaluating Knowledge-Translation Platforms in Low- and Middle-Income Countries' Study. 2010.

[33] Graham ID, Logan J, Harrison MB, Straus SE, Tetroe J, Caswell W, et al. Lost in knowledge translation: Time for a map? J Contin Educ Health Prof. 2006; 26(1): 13-24.

[34] Lavis JN. A Political Science Perspective on Evidence-Based Decision-Making. In: Champagne F, Lemieux-Charles L, editors. Using Knowledge and Evidence in Health Care: Multidisciplinary Perspectives. Toronto. University of Toronto Press. 2004; 311.

[35] Humphries S, Stafinski T, Mumtaz Z, Menon D. Barriers and facilitators to evidence-use in program management: a systematic review of the literature. BMC Health Serv Res. 2014; 14(1): 171.

[36] Higgins JW, Strange K, Scarr J, Pennock M, Barr V, Yew A, et al. 'it's a feel. that's what a lot of our evidence would consist of “: Public health practitioners"' perspectives on evidence"'. Eval Heal Prof. 2011; 34(3): 278-296.

[37] Bowen S, Erickson T, Martens PJ, Crockett S. More than \&quot; using research\&quot;: the real challenges in promoting evidence-informed decision-making. Healthc Policy. 2009; 4(3): 87-102.

[38] Wilson MG, Rourke SB, Lavis JN, Bacon J, Travers R. Community capacity to acquire, assess, adapt, and apply research evidence: a survey of Ontario's HIV/AIDS sector. Implement Sci. 2011; 6: 54.

[39] Rundall TG, Martelli PF, Arroyo L, McCurdy R, Graetz I, Neuwirth EB, et al. The informed decisions toolbox: tools for knowledge transfer and performance improvement. J Healthc Manag. 2007; 52(5): 325-41.

[40] Michie S, West MA. Managing people and performance: An evidence based framework applied to health service organizations. Int J Manag Rev. 2004; 5-6(2): 91-111. 
[41] Craney M. Understanding organizational culture: the key to successful middle manager strategic involvement in health care delivery? J Nurs Manag. 2006; 14(1): 23-33.

[42] Uneke CJ, Ezeoha AE, Ndukwe CD. Development of health policy and systems research in Nigeria: lessons for developing countries' evidence-based health policy making process and practice. Health Policy (New York). 2010; 6.

[43] Uneke CJ, Sombie I, Keita N, Lokossou V, Johnson E, Ongolo-Zogo P. Improving maternal and child health policymaking processes in Nigeria: an assessment of policymakers' needs, barriers and facilitators of evidenceinformed policymaking. Heal Res policy Syst. 2017; 15(Suppl 1): 48.

[44] Green A, Bennett S. Sound Choices: Enhancing Capacity for Evidence-Informed Health Policy. AHPSR Biennual Review. 2007. 